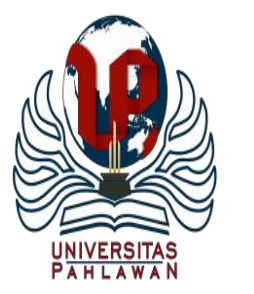

Jurnal Basicedu Volume 4 Nomor 4 Tahun 2020 Halaman 1438 - 1445

JURNAL BASICEDU

Research \& Learning in Elementary Education

https://jbasic.org/index.php/basicedu

\title{
Persepsi Mahasiswa Reguler dan Disabilitas terhadap Layanan Aksesibilitas bagi Penyandang Disabilitas
}

\author{
Suci Indriani ${ }^{1}$, Marlina Marlina ${ }^{2}$ \\ Universitas Negeri Padang, Indonesia ${ }^{1,2}$ \\ E-mail : $\underline{\text { Suciindriani0197@gmail.com }{ }^{1}} \underline{\text { lina muluk@fip.unp.ac.id }{ }^{2}}$
}

\begin{abstract}
Abstrak
Penelitian ini dilakukan berdasarkan permasalahan yang ditemukan di Jurusan Pendidikan Luar Biasa (PLB), terhadap layanan aksesibilitas baik fisik maupun non-fisik yang ada di jurusan yang masih kurang sesuai dengan hambatan yang dialami oleh mahasiswa disabilitas yang ada di jurusan. Penelitian ini bertujuan untuk mengetahui bagaimana persepsi mahasiswa yang ada di jurusan terhadap layanan aksesibilitas baik fisik maupun non-fisik. Metode yang dilakukan dalam penelitian ini adalah metode deskriptif dengan pendekatan kuantitatif, dengan mahasiswa angkatan 2017 dan 2018 sebagai sampelnya. Penelitian ini dilakukan di Jurusan Pendidikan Luar Biasa dengan mahasiswa angkatan 2017 sebanayak 145 orang dan mahasiswa angkatan 2018 sebanyak 138. Teknik pengumpulan data yang digunakan dalam penelitian ini dengan cara penyebaran angket secara online yang ditujukan kepada mahasiswa yang angkatan 2017 dan 2018, yang mana angket tersebut dibagikan melalui sosial media grup masing-masing angkatan. Hasil penelitian ini menunjukan bahwa, sebagian besar mahasiswa setuju dengan adanya pengembangan materi untuk mahasiswa disabilitas, proses belajar mengajar seperti layanan pembelajaran serta media dan sumber belajar yang sesuai untuk hambatan mahasiswa disabilitas yang ada pada jurusan PLB, penilaian pembelajaran sesuai untuk hambatan mahasiswa, pemahaman dan kesadaran dosen dan tenaga kependidikan terhadap mahasiswa disabilitas dan sarana dan prasana yang memadai bagi mahasiswa disabilitas yang ada di jurusan PLB.
\end{abstract}

Kata kunci: persepsi, layanan aksesibilitas, penyandang disabilitas

\begin{abstract}
This research was conducted based on the problems found in the of Special Need Education (SNE), accessibility services both physical and non-physical in the department that is not in accordance with the obstacles experienced by students with disabilities in the department. This study aims to determine how perceptions of students who are in the Department of SNE towards accessibility services both physical and non-physical in the department. The method used in this study is a descriptive method with a quantitative approach, with students in 2017 and 2018 as the sample. This research was conducted in the Department of Special Education where the 2017 class of students consisted of 145 people and the 2018 class year students were 138. The data collection technique used in this study was by distributing online questionnaires aimed at students of the class of 2017 and 2018, where the questionnaire was distributed through social media groups of each group. The results of this study indicate that, most students agree with the development of material for students with disabilities, teaching and learning processes such as the existence of learning services and appropriate media and learning resources for disabilities students in the department of SNE, learning assessment is appropriate for student barriers, understanding and awareness of lecturers and education staff towards students with disabilities and adequate facilities and infrastructures for students with disabilities in the Department of SNE.
\end{abstract}

Keywords: perception, accessibility services, persons with disabilities

Copyright (c) 2020 Suci Indriani, Marlina Marlina

$\triangle$ Corresponding author

Address : Jln. Bandes parak jigarang

Email : Suciindriani0197@gmail.com

ISSN 2580-3735 (Media Cetak)

Phone : : 0895602736347

ISSN 2580-1147 (Media Online)

DOI: https://doi.org/10.31004/basicedu.v4i4.581 
1439 Persepsi Mahasiswa Reguler dan Disabilitas terhadap Layanan Aksesibilitas bagi Penyandang Disabilitas - Suci Indriani, Marlina Marlina

DOI: https://doi.org/10.31004/basicedu.v4i4.581

\section{PENDAHULUAN}

Layanan aksesibilitas bagi mahasiswa disabilitas sangat dibutuhkan dimana hal itu dapat menunjang sistem pendidikan bagi penyandang disabilitas. Hal ini sesuai dengan panduan layanan mahasiswa disabilitas di perguruan tinggi (Kementrian Riset, Teknologi, 2017) bahwa dalam menunjang layanan aksesibilitas bagi mhasiswa disabilitas diperlukan unit layanan disabilitas. Dimana tugasnya meliputi plan (merencanakan), coordinate (mengkoordinasi), evaluate (evaluasi) dan supervise (mengawasi) program layanan yang sudah dilakukan.

Disabilitas menurut Convention on The Rights of Persons with Disabilities adalah orangorang yang memiliki keterbatasan mental, fisik, intelektual, atau sensorik dan dialami dalam jangka waktu lama. Seseorang disebut disabilitas apabila mereka tidak dapat beradaptasi dengan penuh dalam lingkungannya. Sistem pendidikan tidak terkecuali pada pendidikan perguruan tinggi, di perguruan tinggi perlu berorientasi pada inklusi untuk membangun masyarakat inklusif guna melawan sikap diskriminatif. Pendidikan untuk semua adalah sebuah sistem pendidikan yang bisa diakses oleh semua kalangan. Tidak ada diskriminasi diantaranya, sehingga terwujudlah masayrakat ynag inklusif dimana perbedaan dapat dihargai dalam satu kesatuan kehidupan. Kemenristekdikti mencatat adanya empat ratus satu mahasiswa disabilitas dari seratus lima puluh dua perguruan tinggi. Mereka berasal dari berbagai jenis hambatan mereka tersebar di berbagai program studi di Universitas tersebut (Kementrian Riset, Teknologi, 2017).
Saat ini, kesempatan pendidikan bagi penyandang disabilitas telah terbuka dan cukup luas. Ini merupakan bukti dari kepedulian dan komitmen pemerintah dan masyarakat guna membantu para penyandang disabilitas memenuhi haknya memperoleh pendidikan untuk hidup yang lebih baik. Pada tahun 2017 Kementrian Riset, Teknologi, dan Pendidikan Tinggi menerbitkan Permenristekdikti Nomor 46 tahun 2017 tentang Pendidikan Khusus dan Pendidikan Layanan Khusus di Perguruan Tinggi. Kehadiran Permenristekdikti nomor46/2017 menjadi sangat penting bagi dunia pendidikan tinggi, karena saat ini semakin banyak warga negara disabilitas yang menempuh pendidikan di Perguruan tinggi (Kementrian Riset, Teknologi, 2017).

Berdasarkan studi pendahuluan yang peneliti lakukan di Jurusan PLB terhadap layanan aksesibilitas mahasiswa disabilitas yang terkait seperti, isi pembelajaran, dalam pengembangan materi untuk mahasiswa disabilitas perlu ditingkatkan yaitu dengan memodifikasinya seperti menduplikasikannya atau mensubstisikan materi dengan materi yang setara, hal ini akan sejalan dengan proses belajar mengajar yang dilakukan karena sesuai dengan media dan sumber pembelajaran yang diperlukan oleh mahasiswa disabilitas dan berpengaruh kepada penilai pembelajaran yang dilaksanakan oleh mahasiswa disabilitas karena adanya evaluasi pengembangan untuk mahasiswa disabilitas karena sesuai dengan hambatan yang dialami, dosen dan tenaga kependidikan juga harus berperan andil dalam membantu kegiatan mahasiswa baik itu dalam segi akademis maupun non akademis, dan sarana 
1440 Persepsi Mahasiswa Reguler dan Disabilitas terhadap Layanan Aksesibilitas bagi Penyandang Disabilitas - Suci Indriani, Marlina Marlina

DOI: https://doi.org/10.31004/basicedu.v4i4.581

prasarana juga dibutuhkan guna menunjang kegiatan mahasiswa terutama mahasiswa yang mengalami hambatan. Layanan aksesibilitas fisik dan non-fisik untuk mahasiswa disabilitas ini sangat penting dalam menunjang pendidikan di Perguruan Tinggi. Hal itu dikarenakan kesempatan pendidikan bagi penyandang disabilitas sudah terbuka luas dan seiring berjalannya waktu layanan aksesbilitas juga harus lebih ditingkatkan untuk memudahkan akses bagi penyandang disabilitas.

Tujuan dari peneliti ini untuk mengungkapkan bagaimana persepsi mahasiswa reguler dan disabilitas terhadap layanan aksesibilitas penyandang disabilitas di jurusan pendidikan luar biasa. Persepsi yang dimaksud adalah bagaiamana pandangan atau tanggapan seseorang terhadap sesuatu yang dialamai langsung oleh seseorang terhadap apa yang ada di sekitarnya sehingga memperoleh informasi mengenai sesuatu.

\section{METODE}

Jenis penelitian yang digunakan adalah deskriptif kuantitatif. Metode yang digunakan adalah metode deskriptif dengan pendekatan kuantitatif. Penelitian deskriptif yaitu, penelitian yang mengungkapkan sesuatu secara mendalam dan detail mengenai peristiwa atau fenomena yang terjadi dari berbagai aspek penelitian (Nasehudin \& Gozali, 2012).

Teknik dalam pengambilan sampel dalam penelitian ini adalah mahasiswa reguler dan disabilitas yang ada di Jurusan PLB. Dalam menentukan subjek penelitian, peneliti mneggunakan teknik purposive sampling. Teknik purposive sampling itu sendiri adalah teknik pengambilan sampel dengan pertimbangan tertentu, maka yang menjadi tujuan purposive sampling pada penelitian ini ialah mahasiswa angkatan 2017 dan 2018 dengan pertimbangan, yaitu, mahasiswa angkatan 2018 dan 2019 yang masih aktif menjadi mahasiswa di jurusan PLB, mahasiswa angkatan 2017 dan 2018 sudah berpengalaman dan paham dengan ke PLB-an. Berikut adalah data mahasiswa angkatan 2017 dan 2018 :

Tabel 1. Jumlah Data Mahasiswa Angkatan 2017 dan 2018

\begin{tabular}{|c|c|c|}
\hline No & Mahasiswa angkatan & Jumlah mahasiswa \\
\hline 1 & 2017 & 145 \\
\hline 2 & 2018 & 138 \\
\hline
\end{tabular}

Teknik pengumpulan data yang digunakan dalam penelitian ini, yaitu dengan cara penyebaran angket secara online (https://forms.gle/VwyoHo5M9aJLPH3w9) yang diberikan kepada mahasiswa angkatan 2017 dan 2018. Angket online ini bertujuan untuk mengukur persepsi mahasiswa terhadap layanan aksesibilitas mahsiswa disabilitas di jurusan PLB. Angket merupakan teknik pengumpulan data yang dilakukan dengan cara memberikan pertanyaan atau pernyataan kepada responden untuk dijawabnya (Sugiyono, 2016).

Skala pengukuran yang digunakan untuk angket oleh peneliti adalah skala Likert dengan alternatif jawaban sangat setuju, setuju, tidak setuju, sangat tidak setuju.untuk lebih jelasnya dalam pemberian skor untuk yang sangat setuju 
1441 Persepsi Mahasiswa Reguler dan Disabilitas terhadap Layanan Aksesibilitas bagi Penyandang Disabilitas - Suci Indriani, Marlina Marlina

DOI: https://doi.org/10.31004/basicedu.v4i4.581

diberi nilai 4 dan untuk yang sanagat tidak setuju diberi nilai 1.

Data analisis menggunakan teknik perhitungan persentase. Penelitian yang mampu menetukan sesuatu apa adanya terhadap apa yang diteliti, maka pada analisis datanya menggunakan persentase (S Arikunto, 2005). Teknik analisis data dalam penelitian dapat menggunakan persentase (Nasehudin \& Gozali, 2012). Berikut rumusan persentase dibawah ini:

$P=\frac{F}{N} \times 100$

Keterangan :

$\mathrm{P}=$ Persentase

$\mathrm{F}=$ Frekuensi Jawaban

$\mathrm{N}=$ Jumlah Keseluruhan Responden

Berikut kriteria yang dipakai adalah menurut (Suharsimi Arikunto, 2013) sebagai berikut.

Tabel 2. Kriteria Pengelolaan Data Hasil Penilaian

\begin{tabular}{|l|l|}
\hline \multicolumn{1}{|c|}{ Persentase } & \multicolumn{1}{c|}{ Kategori } \\
\hline $100 \%$ & Seluruh \\
\hline $80-99 \%$ & Hampir Keseluruhan \\
\hline $60-70 \%$ & Sebagian Besar \\
\hline $40-59 \%$ & Sebagian \\
\hline $20-39 \%$ & Hampir sebagian \\
\hline $1-19 \%$ & Sebagian Kecil \\
\hline
\end{tabular}

\section{HASIL DAN PEMBAHASAN}

\section{Isi Pembelajaran}

Pada aspek ini berisikan tentang bagaimana pengembangan materi pembelajaran untuk mahasiswa disabilitas.Terdapat indikator yaitu pengembangan materi pembelajaran mahasiswa disabilitas. Berdasarkan data yang dikumpulkan pada isi pembelajaran ini dapat disimpulkan bahwa $(56,4 \%)$ sebagian mahasiswa setuju dengan pengembangan materi untuk mahasiswa disabilitas. Berikut grafiknya :

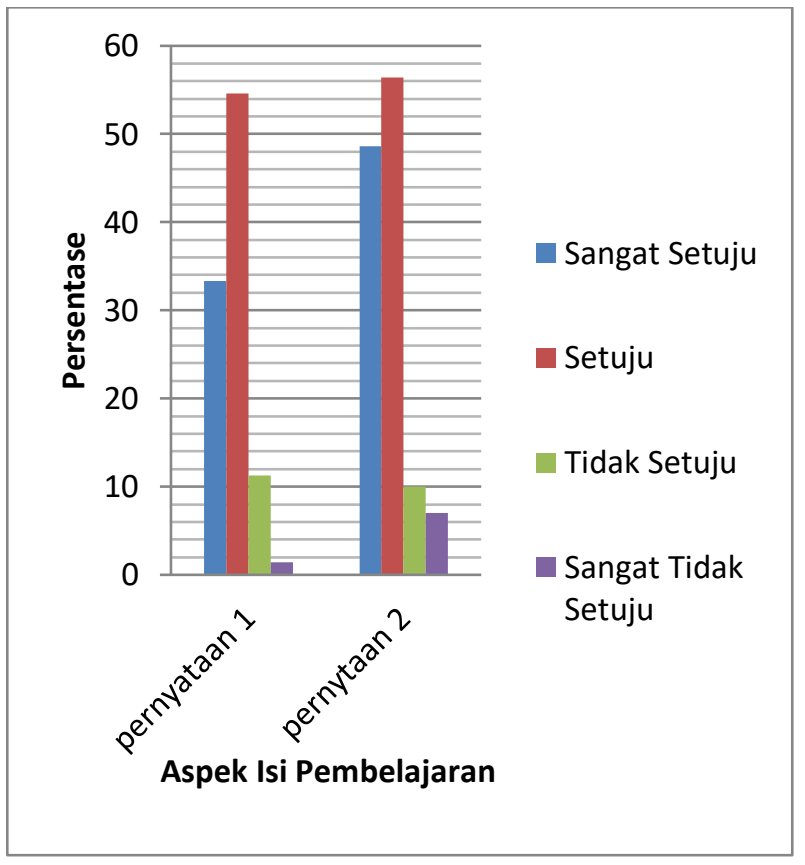

Grafik 1. Aspek Isi Pembelajaran

\section{Proses Belajar Mengajar}

Pada aspek ini berisikan tentang implementasi dari proses belajar mengajar yang ada. Terdapat dua indikator yaitu layanan pembelajaran serta media dan sumber belajar. Berdasarkan data yang telah didapat pada proses belajar mengajar ini dapat disimpulkan bahwa persepsi sebagain $(56,3 \%)$ mahasiswa setuju dengan proses belajar mengajar yang dilakukan dosen. Berikut grafiknya: 
1442 Persepsi Mahasiswa Reguler dan Disabilitas terhadap Layanan Aksesibilitas bagi Penyandang Disabilitas - Suci Indriani, Marlina Marlina

DOI: https://doi.org/10.31004/basicedu.v4i4.581

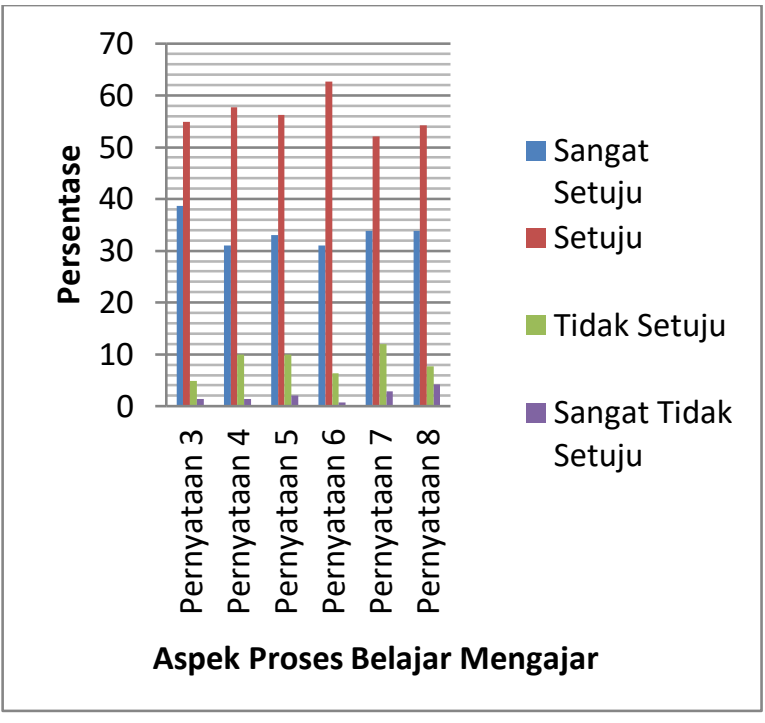

Grafik 2. Aspek Proses Belajar Mengajar

\section{Penilaian Pembelajaran}

Pada aspek ini berisikan tentang pendapat mahasiswa pada penilaian pembelajaran yang ada. Terdapat satu indikator yaitu pelaksanaan evaluasi pembelajaran. Berdasarkan data yang telah didapat pada penilaian pembelajaran ini, dapat disimpulkan bahwa persepsi sebagian $(58,5 \%)$ mahasiswa setuju terhadap pemberian penilaian pembelajaran. Berikut grafiknya:

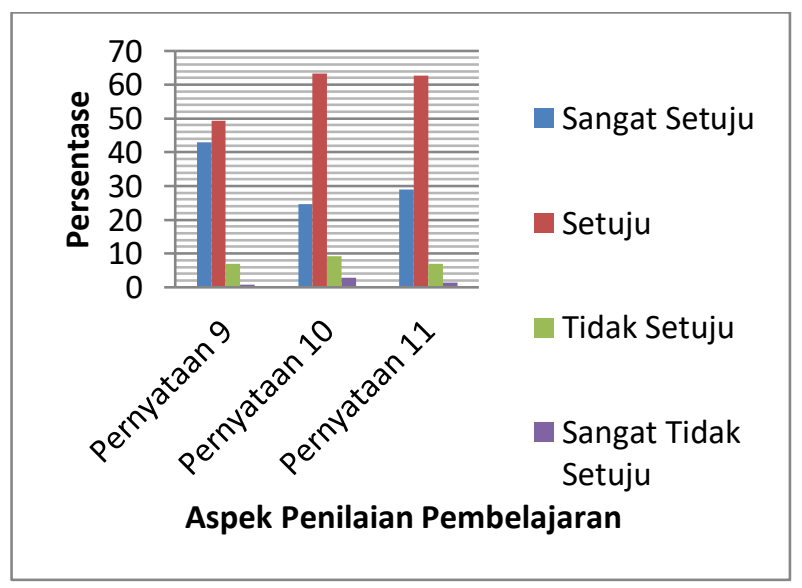

Grafik 3. Aspek Penilaian Pembelajaran

\section{Dosen dan Tenaga Kependidikan}

Pada aspek ini berisikan tentang persepsi mahasiswa terhadap dosen dan tenaga kependidikan. Terdapat satu indikator yaitu pemahaman dan kesadaran tentang mahasiswa disabilitas. Berdasarkan data yang telah didapat pada penilaian pembelajaran ini, dapat disimpulkan bahwa persepsi sebagian $(58,4 \%)$ mahasiswa setuju dengan persepsi mahasiswa terhadap dosen dan tenaga kependidikan. Berikut grafiknya :

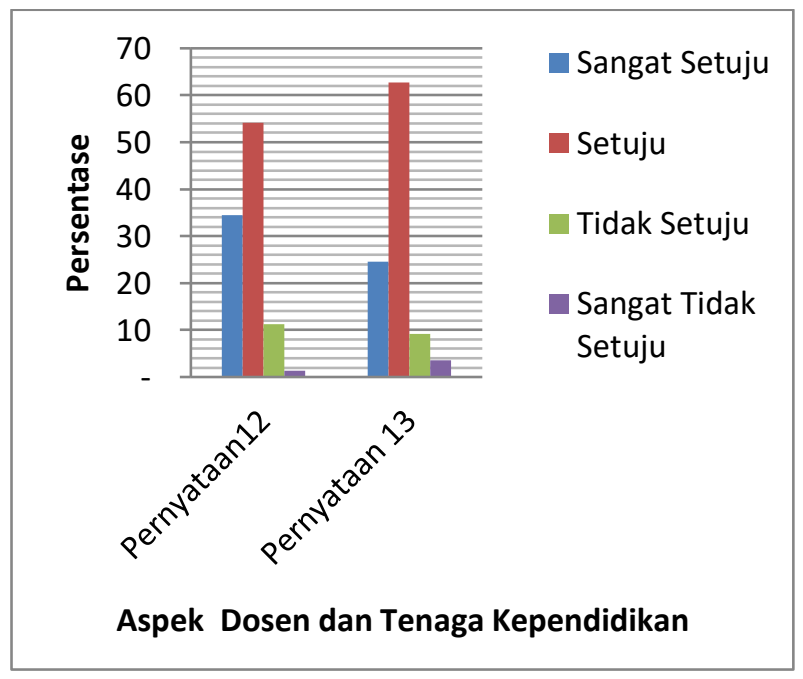

Grafik 4. Aspek Dosen dan Tenaga Kependidikan

\section{Sarana dan Prasarana}

Pada aspek ini berisikan tentang persepsi mahasiswa terhadap sarana dan prasarana. Terdapat satu indikator yaitu penataan lingkungan fisik yang aksesibel. Berdasarkan data yang telah didapat pada saea dan prasarana ini, dapat disimpulkan bahwa persepsi sebagain $(55,8 \%)$ persepsi mahasiswa terhadap sarana dan prasana. Berikut grafiknya: 
1443 Persepsi Mahasiswa Reguler dan Disabilitas terhadap Layanan Aksesibilitas bagi Penyandang Disabilitas - Suci Indriani, Marlina Marlina

DOI: https://doi.org/10.31004/basicedu.v4i4.581

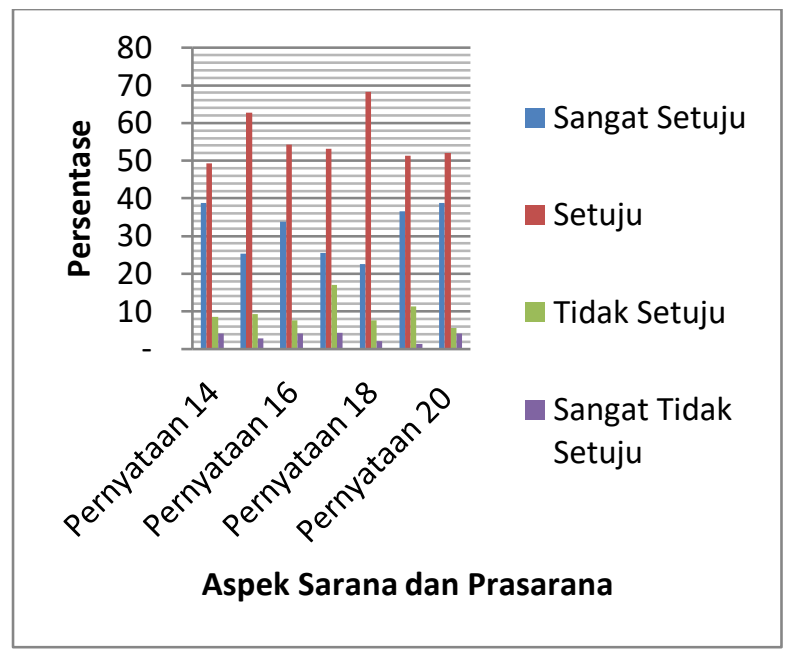

Grafik 5. Aspek Sarana dan Prasarana

\section{Pembahasan}

Berdasarkan penelitian yang telah dilakukan, ditemui bahwa persepsi mahasiswa reguler dan disabilitas dalam layanan aksesibilitas sebagian besar mahasiswa setuju dengan adanya layanan aksesibilitas yang diberikan untuk mahasiswa disabilitas yang ada dikampus baik itu dari segi fisik maupun non-fisik.

\section{Isi Pembelajaran}

Berdasarkan hasil penelitian tentan persepsi mahasiswa reguler dan disabilitas terhadap layanan aksesibilitas bagi penyandang disabilitas dilihat dari isi pembelajarannya, sebagian mahasiswa setuju untuk pengembangan isi pembelajaran sesuai dengan hambatan yang dialami oleh mahasiswa. Pengembangan materi untuk mahasiswa disabilitas perlu dimodifikasi dengan cara menduplikasikannya atau dengan cara mensubstitusikannya. Untuk pengembangan materi yang diduplikasi adalah tidak ada perbedaan jenis, kedalaman, dan keluasan materi untuk mahasiswa disabilitas tetapi pada modifikasi proses belajar mengajarnya (Maghfiroh, 2013).

\section{Proses Belajar Mengajar}

Berdasarkan hasil penelitian tentang persepsi mahasiswa reguler dan disabilitas terhadap layanan aksesibilitas bagi penyandang disabilitas dilihat dari proses belajar mengajar, sebagian mahasiswa setuju untuk adanya layanan dan media pembelajaran yang sesuai dengan hambatan yang dimiliki oleh mahasiswa disabilitas. Layanan pembelajaran dan media pembelajaran juga di perbaiki. Karena, dengan adanya layanan dan media pembelajaran yang sesuai dengan hambatan yang dialami oleh mahasiswa, maka mahasiswa disabilitas akan terbantu dengan layanan dan media tersebut (Maghfiroh, 2013).

\section{Penilaian Pembelajaran}

Berdasarkan hasil penelitian tentang persepsi mahasiswa reguler dan disabilitas terhadap layanan aksesibilitas bagi penyandang disabilitas dilihat dari penilaia pembelajaran, sebagian mahasiswa setuju dengan adanya penilaian pembelajaran. Adanya pengembangan evaluasi untuk mahasiswa disabilitas, penilian evalusi yang dimaksaud adalah penilaian yang diberikan oleh tenaga pengajar kepada mahasiswa disabilitas sesuai dengan hambatan yang dialami oleh mahasiswa itu sendiri.

\section{Dosen dan Tenaga Kependidikan}

Berdasarkan hasil penelitian tentang persepsi mahasiswa reguler dan disabilitas terhadap layanan aksesibilitas bagi penyandang disabilitas dilihat dari dosen dan tenaga kependididkan sebagian mahasiswa setuju 
1444 Persepsi Mahasiswa Reguler dan Disabilitas terhadap Layanan Aksesibilitas bagi Penyandang Disabilitas - Suci Indriani, Marlina Marlina

DOI: https://doi.org/10.31004/basicedu.v4i4.581

apabila dosen dan tenaga kependidikan berperan andil terhadap mahasiswa yang mengalami kesulitan dalam melakukan kegiatan di kampus. Peran andil dosen dan tenaga kepedidikan juga perlu, karena mahasiswa disabilitas akan sangat terbantu jika dosen dan tenaga pendidik paham dan mengerti dengan hambatan yang dialami oleh mahasiswa disabilitas (Marlina \& Kusumastuti, 2019); (Marlina, Efrina, \& Kusumastuti, 2019).

\section{Saran dan Prasarana}

Berdasarkan hasil penelitian tentang persepsi mahasiswa reguler dan disabilitas terhadap layanan aksesibilitas bagi penyandang disabilitas dilihat dari sarana dan prasarana, sebagaia mahasiswa setuju dengan peningkatan sarana dan prasaran untuk mahasiswa disabilitas. Sarana dan prasarana perlu ditingkatkan guna menunjang aksesibilitas bagi mahasiswa disabilitas. Hal ini dikarenakan melihat kondisi serta hambatan yang dialami oleh mahasiswa, untuk itu perlu adanya peningkatan pada sarana dan prasarana ini.

Sebagaimana yang telah dipaparkan terkait dengan aksesibilitas fisik terdapat kebijakan negara berupa Peraturan Menteri Pekerjaan Umum RI No. 30 tahun 2006 tentang pedoman teknis fasilitas dan aksesibilitas pada bangunan gedung dan lingkungan. Permen PU ini mengatur persyaratan teknis fasilitas dan aksesibilitas pada bangunan gedung dan lingkungan baik itu ruangan terbuka dan penghijauan yang dipergunakan atau dikunjungi orang, khususnya agar mudah diakses oleh lansia dan penyandang disabilitas
(Syafi'ie, 2014). Contoh bagaimana aksesibilitas bangunan dan lingkungan yang aksesibel disekitar kampus yang meliputi sarana dan prasarana fisik yaitu, ram atau tangga landai, ini diperlukan agar bisa diakses oleh disabilitas pengguna kursi roda atau bagi tunanetra, toilet khusus. Toilet ini memiliki ruang yang lebar agar dapat digunakan oleh pengguna kursi roda dan memiliki closet duduk yang dilengkapi rail pengaman agar mereka bisa berpegangan, ruangan kelas yang perlu diberikan label berupa huruf Braille bagi tunanetra. Layanan sarana dan prasarana tersebut sangat dibutuhkan bagi penyandang disabilitas, karena itu dapat menunjang kegiatan mereka selama mereka berada di kampus.

\section{SIMPULAN}

Dari hasil penelitian, yang terdiri dari enam indikator, yaitu: Pengembangan mataeri untuk mahasiswa disabilitas, Layanan pembelajaran, Media dan sumber pembelajaran, pelaksanaan evaluasi, Pemahaman dosen dan kesadaran tentang mahasiswa disabilitas, Penataan lingkungan fisik yang aksesibel.

Persepsi mahasiswa terhadap layanan aksesibilitas dilihat dari isi pembelajaran pada kategori sebagian. Hal ini menunjukan bahwa sebagian mahasiswa setuju dengan adanya Pengembangan materi untuk mahasiswa disabilitas. Persepsi mahasiswa terhadap layanan aksesibilitas dilihat dari proses belajar mengajar, sebagian mahasiswa setuju dengan pengembangan pada layanan proses belajar mengajar dengan 
1445 Persepsi Mahasiswa Reguler dan Disabilitas terhadap Layanan Aksesibilitas bagi Penyandang Disabilitas - Suci Indriani, Marlina Marlina

DOI: https://doi.org/10.31004/basicedu.v4i4.581

dosen memberikan media atau bahan pembelajaran yang sesuai dengan kebutuhan mahasiswa disabilitas. Persepsi mahasiswa terhadap layanan aksesibilitas dilihat dar penilaian pembelajaran yang mana sebagian mahasiswa setuju untuk pemberian nili kepada mahasiswa disabilitas sesuai dengan hambatan yang dialami. Persepsi mahasiswa terhadap layanan aksesibilitas dilihat dari dosen dan tenaga kependidikan sebagian dari mahasiswa setuju dengan peran andil dosen dan tenaga kependidikan kepada mahasiswa disabilitas. Persepsi mahasiswa terhadap layanan aksesibilitas dilihat dari sarana dan prasana sebagian besar mahasiswa setuju dengan sarana dan prasarana yang ada, namu lanagkah lebih baiknya jika ditambahkan lagi layanan saran dan prasaran untuk mahasiswa disabilitas karena selaian aksesibilitas non fisik aksesibilitas fisik juga dibutuhkan bagi mahasiswa disabilitas.

Mahasiswa disabilitas berhak mendapatkan pendidikan yang berkualitas di perguruan tinggi. Kualitas pendidikan memerlukan efisiensi dan efektivitas yang dapat diperoleh dengan orientasi terhadap pendidikan inklusi. Hal ini membutuhkan peran berbagai pihak dalam pemberian layanan pendidikan sesuai dengan Panduan Layanan Mahasiswa Disabilitas. Sebagian besar mahasiswa juga setuju dengan pelayanan untuk mahasiswa disabilitas agar mereka nyaman sesuai dengan panduan Layanan Mahasiswa Disabilitas di Perguruan Tinggi.

\section{DAFTAR PUSTAKA}

Andayani, R. (2010). Muhrisun, Membangun Kampus Inklusif, Best Practices
Pengorganisasian Unit Layanan Difabel[GEN]. Yogyakarta: Pusat Studi dan Layanan Difabel, Pertuni, ICEVI dan Nippon ....

Deni Darmawan. (2013). Metode Penelitian Kuantitatif. Bandung: PT Remaja Rosdakarya.

Kementrian Riset, Teknologi, dan P. T. D. J. P. dan K. (2017). Panduan Layanan Mahasiswa Disabilitas di Perguruan Tinggi. Jakarta.

Maghfiroh, L. (2013). Pengembangan Kurikulum Model DMSO (Duplikasi, Modifikasi, Substitusi, Omisi) dan Implementasinya dalam Pembelajaran Pendidikan Agama Islam Di SMP Galuh Handayani: Penyelenggara Pendidikan Inklusif [DISS]. UIN Sunan Ampel Surabaya.

Marlina, M., Efrina, E., \& Kusumastuti, G. (2019). Differentiated Learning for Students with Special Needs in Inclusive Schools. 5th International Conference on Education and Technology (ICET 2019). Atlantis Press.

Marlina, M., \& Kusumastuti, G. (2019). Social Participation of Students with Special Educational Needs in Inclusive Elementary Schools/Specialiujų Ugdymosi Poreikiu Turinčiu Mokinių Socialinis Dalyvavimas Inkliuzinèje Pradinio Ugdymo Mokykloje. Specialusis Ugdymas/Special Education, 1(39), 109-132.

Nasehudin, T. S., \& Gozali, N. (2012). Metode Penelitian Kuantitatif. Bandung: CV Pustaka Setia.

Nazir, M. (2014). Metode Penelitian. Bogor: Ghalia Indonesia.

Soleh, A. (2014). Kebijakan Perguruan Tinggi Negeri Yogyakarta Terhadap Penyandang Disabilitas [JOUR]. Jurnal Pendidikan Islam, 3(1), 1-30.

Syafi'ie, M. (2014). Pemenuhan Aksesibilitas Bagi Penyandang Disabilitas [JOUR]. Inklusi, 1(2), 269-308. 